\title{
ChemComm
}

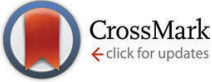

Cite this: Chem. Commun., 2015, 51, 5751

Received 16th December 2014, Accepted 19th February 2015

DOI: $10.1039 / c 4 c c 10032 h$

www.rsc.org/chemcomm

\section{Asymmetric hydroamination catalyzed by a new chiral zirconium system: reaction scope and mechanism $\dagger$}

\author{
Xiaoguang Zhou, ${ }^{\text {ab }}$ Bing Wei, ${ }^{\text {ab }}$ Xiu-Li Sun, ${ }^{a}$ Yong Tang ${ }^{\star a}$ and Zuowei Xie ${ }^{\star b c}$
}

A new class of chiral zirconium complexes supported by chiral tridentate $\left[\mathrm{O}^{-} \mathrm{NO}^{-}\right.$]-type of ligands derived from amino acids were synthesized and structurally characterized. They catalyzed asymmetric hydroamination/cyclization of primary aminoalkenes to give five- and six-membered $\mathrm{N}$-heterocyclic amines with up to $94 \%$ ee.

Hydroamination as a highly atom-economic reaction for efficient synthesis of nitrogen containing compounds has received great attention. In particular, chiral intramolecular hydroamination provides a convenient way to obtain chiral N-heterocycles, which plays an important role in pharmaceuticals. ${ }^{1}$ Since the first report on asymmetric hydroamination in 1992 based on chiral ansa-lanthanocenes, ${ }^{2}$ several chiral catalyst systems have been developed, including group 4 metals, ${ }^{3}$ alkaline earth metals, ${ }^{4}$ alkali metals, ${ }^{5}$ late transition metals, ${ }^{6}$ rare earth metals ${ }^{2,7-12}$ and chiral Brønsted acids. ${ }^{13}$ Though significant progress has been made in the past decade in this field, the reported enantioselective systems remain very limited. In view of the recent progress in asymmetric catalysis, ${ }^{14}$ it is envisioned that new ligand design, new catalyst synthesis, and mechanism tests may offer strategies for addressing challenging issues in asymmetric olefin hydroamination, thus further advancing this field.

Very recently, we reported a highly active cationic zirconium system based on a tridentate $\left[\mathrm{O}^{-} \mathrm{N}^{-} \mathrm{S}\right]$ ligand for catalytic hydroamination with a broad substrate scope from primary amines to secondary amines, and from terminal alkenes to much less reactive internal alkenes. ${ }^{15}$ This system also catalyzed tandem intramolecular hydroamination of primary aminoalkenes to give bicyclic amines, and was tolerant of many functional groups.

\footnotetext{
${ }^{a}$ State Key Laboratory of Organometallic Chemistry, Shanghai Institute of Organic Chemistry (SIOC), Chinese Academy of Sciences, 345 Lingling Lu, Shanghai 200032, P. R. China. E-mail: tangy@sioc.ac.cn

${ }^{b}$ Shanghai-Hong Kong Joint Laboratory in Chemical Synthesis, SIOC, P. R. China

${ }^{c}$ Department of Chemistry, The Chinese University of Hong Kong, Shatin,

New Territories, Hong Kong, P. R. China. E-mail: zxie@cuhk.edu.hk

$\dagger$ Electronic supplementary information (ESI) available: Complete experimental details, characterization data, kinetic plots, and crystallographic data. CCDC 1016330-1016342 for 1-3, 4a,b,c,d, 5a,b,c,d, 8, and 9. For ESI and crystallographic data in CIF or other electronic format see DOI: 10.1039/c4cc10032h
}

We wondered if chiral ligands derived from such a tridentate backbone system would offer both high catalytic activity and enantioselectivity in asymmetric hydroamination. Here we report the new chiral catalyst systems for asymmetric hydroamination of aminoalkenes with up to $94 \%$ ee and $\geq 95 \%$ conversion. The reaction mechanism is also discussed.

Initially, a series of new chiral auxiliary $\left[\mathrm{O}^{-} \mathrm{N}^{-} \mathrm{O}\right]$ ligands were synthesized via the condensation of salicylaldehyde with $O$-alkylated chiral aminoalcohol, followed by reduction with $\mathrm{LiAlH}_{4}$ (see ESI $\dagger$ ). They were treated with 1 equiv. of tetrabenzyl-zirconium in toluene to give new chiral dibenzyl zirconium complexes 1-4 (Chart 1). Screening results on catalytic hydroamination of 2,2-diphenyl-4pentenamine (6A) indicated that $4 \mathbf{b}$ offered the best ee value and the lability of the $\mathrm{OR}^{2}$ group disfavored the chiral induction (Table S3 in ESI†). To fix this problem, a covalent bond between the $\mathrm{Zr}$ atom and $\mathrm{O}(2)$ was desirable, which led to the design of a new ligand backbone. Subsequently, a series of new ligands with a $\left[\mathrm{O}^{-} \mathrm{NO}^{-}\right]$backbone were prepared. Their $\mathrm{Zr}$ complexes $\mathbf{5 a - f}$ were also synthesized and characterized by various spectroscopic data and single-crystal X-ray analyses (Fig. S8-S11 in ESI $\dagger$ ). Scheme 1 shows the screening results of $\mathbf{5 a}-\mathbf{f}$. The enantioselectivity of the reaction was greatly improved, $74 \%$ ee for $\mathbf{5 a}, 89 \%$ ee for $\mathbf{5 b}$ and $68 \%$ ee for 5c. It was clear that gem-disubstituents had a large impact on ee values with gem-dimethyl being the best choice. Replacement of a five-membered N-heterocycle by a six-membered one (5e) or a fused five-membered ring (5f) offered similar enantioselectivity. After identifying $\mathbf{5 b}$ as the best catalyst for hydroamination of $\mathbf{6 A}$, the effect of reaction temperature on enantioselectivity was examined and the results are listed in Table S4 (ESI $\dagger$ ).

Under the optimal reaction conditions, several substrates were examined, and the results are summarized in Table 1. Both five- and six-membered N-heterocyclic ring products were generated with up

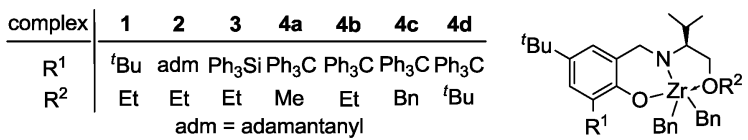

Chart 1 Chiral Zr complexes 1-4. 



Scheme 1 Screening results of asymmetric hydroamination catalyzed by $\mathbf{5 a}-\mathbf{f}$.

to $94 \%$ ee. The substrate $6 \mathrm{~B}$ gave spiro[4,5] product $7 \mathrm{~B}$ in $93 \%$ ee (entry 2), and the substrate $6 \mathrm{C}$ offered spiro[4,4] product $7 \mathrm{C}$ in $87 \%$ ee (entry 3). Desymmetrization with the two allyl groups in aminodiene 6F produced both diastereomers with $88 \%$ ee and $92 \%$ ee, respectively, whereas the diastereoselectivity was low (1:1.7) (entry 6). Upon replacing phenyl in $\mathbf{6 F}$ with methyl, even higher ee values of $90 \%$ and 93\% were achieved (entry 5). The gem-dialkyl effect was also observed. As anticipated, replacement of gem-diphenyl substitutes in $\mathbf{6 A}$ by gemdimethyl-ones resulted in a much lower activity (entry 4). Complex 5e was found to give $\mathbf{7 G}$ in $66 \%$ ee, which represents the best enantioselectivity so far observed for the hydroamination of $\mathbf{6 G}$ (entry 7 ).

Since $5 \mathbf{b}$ did not show catalytic activity toward secondary aminoalkenes, it seemed that the above $[\mathrm{ONO}] \mathrm{Zr}\left(\mathrm{CH}_{2} \mathrm{Ph}\right)_{2}$ system might proceed via a Zr-imido intermediate. Many attempts to isolate the

Table 1 Substrate scope of hydroamination catalyzed by $\mathbf{5 b}$

\begin{tabular}{|c|c|c|c|c|}
\hline Entry & Substrate & Product & Time (h) & Yield $^{f} /$ ee $^{d}(\%)$ \\
\hline $1^{c}$ & $6 \mathrm{~A}$ & & 19 & $84 / 94$ \\
\hline $2^{a, e}$ & 6B & & 21 & $97 / 93$ \\
\hline $3^{a, e}$ & & & 72 & $91 / 87$ \\
\hline $4^{a, e}$ & 6D & N-Ts & 120 & $96 / 89$ \\
\hline $5^{a, e}$ & 6E & & 89 & $\begin{array}{l}89 / 90,93 \\
\mathrm{dr}=1: 1.2\end{array}$ \\
\hline $6^{a, e}$ & $6 \mathrm{~F}$ & & 24 & $\begin{array}{l}91 / 88,92 \\
\mathrm{dr}=1: 1.7\end{array}$ \\
\hline $7^{b}$ & $6 G$ & $7 \mathrm{G}$ & 2 & $91 / 66$ \\
\hline
\end{tabular}

${ }^{a}$ Temp. $=85{ }^{\circ} \mathrm{C} .{ }^{b}$ Using $10 \mathrm{~mol} \% 5$ e at $130{ }^{\circ} \mathrm{C} .{ }^{c}$ Temp. $=70{ }^{\circ} \mathrm{C} .{ }^{d}$ The ee value measured by chiral HPLC. ${ }^{e}$ Products were converted to $N$-Ts compounds and the ee value was measured by chiral HPLC, the dr value was determined by the analyses of the ${ }^{1} \mathrm{H}$ NMR spectrum of the crude product. ${ }^{f}$ Isolated yield.



Scheme 2 Reaction of $\mathbf{8}$ with $t-\mathrm{BuNH}_{2}$.

reaction intermediate from the stoichiometric reaction of $5 \mathbf{b}$ with $6 \mathrm{~A}$ were unsuccessful. We then prepared an achiral Zr complex 8 with the same $\left[\mathrm{O}^{-} \mathrm{NO}^{-}\right]$backbone. It could catalyze the hydroamination of $\mathbf{6 A}$ to a racemic mixture of $7 \mathbf{A}$ with a comparable activity to $\mathbf{5 b}$.

Reaction of $\mathbf{8}$ with an excess amount of $t-\mathrm{BuNH}_{2}$ in toluene at room temperature gave an imido-bridged zirconium amide complex 9 in $44 \%$ yield. Complex 9 also catalyzed the hydroamination of $\mathbf{6 A}$ to offer $( \pm) 7 \mathbf{A}$ in a similar activity to that of $\mathbf{8}$. Single-crystal X-ray analyses reveal that 9 is a dimer with bridging imido ${ }^{t} \mathrm{BuN}$ and alkoxy units, respectively (Scheme 2). One of the $\mathrm{Zr}$ atoms is five coordinated, and the other is six coordinated. In addition, each $\mathrm{Zr}$ atom is $\sigma$-bonded to one amido unit ${ }^{t} \mathrm{BuNH}$, and the two ${ }^{t} \mathrm{BuNH}$ moieties are oriented in trans positions (Fig. S13 in ESI $\dagger$ ).

To gain further insight into the reaction mechanism, a kinetic analysis of hydroamination/cyclization of aminoalkene $6 \mathrm{~A}$ catalyzed by $\mathbf{5 b}$ was performed for the determination of an empirical rate law using in situ ${ }^{1} \mathrm{H}$ NMR monitoring. Ferrocene was employed as an internal ${ }^{1} \mathrm{H}$ NMR integration standard, as it was readily differentiated from the substrate, product, and catalyst resonances in deuterated toluene. The appearance of the product $7 \mathrm{~A} \mathrm{CH}_{2} \mathrm{CH}$ signal was monitored as a function of time and normalized versus the internal standard. ${ }^{16}$

The results show that there is a first-order dependence on both catalyst and substrate concentration, giving the empirical rate law in the following equation on the basis of initial rate measurements: rate $=k_{\text {obs }}$ [catalyst][substrate].

To gauge the effect of $N$-deuteration on the reaction catalyzed by $\mathbf{5 b}$, the conversion of $d_{2}-\mathbf{6 A}$ was studied (Scheme 3 ). It was found that the cyclization of $N$-deuterated $d_{2}-\mathbf{6 A}$ was much slower than for the proteo counterpart 6A, giving $k_{\mathrm{H}} / k_{\mathrm{D}}=5.2$ at $60{ }^{\circ} \mathrm{C}$ (see Fig. S19 in ESI $\dagger$ ).

To further probe the nature of the turnover-limiting step, the temperature dependence of the cyclization rate of $\mathbf{6 A}$ was investigated by determining the $k_{\text {obs }}$ values at $50{ }^{\circ} \mathrm{C}, 60{ }^{\circ} \mathrm{C}, 70{ }^{\circ} \mathrm{C}$ and $80{ }^{\circ} \mathrm{C}$ (see Fig. S20 in ESI $\dagger$ ). The Eyring plot generated from these data is shown in Fig. S21 in ESI. $\dagger$ The calculated thermodynamic parameters are $\Delta H^{\neq}=9.9 \pm 0.3 \mathrm{kcal} \mathrm{mol}^{-1}$ and $\Delta S^{\neq}=-53.4 \pm$ 0.9 cal $\mathrm{K}^{-1} \mathrm{~mol}^{-1}$, which are very comparable to $\Delta H^{\neq}=6.7 \pm$ $0.2 \mathrm{kcal} \mathrm{mol}^{-1}$ and $\Delta S^{\neq}=-43 \pm 7 \mathrm{cal} \mathrm{K}^{-1} \mathrm{~mol}^{-1}$ observed for the $\left[\mathrm{PhB}\left(\mathrm{C}_{6} \mathrm{H}_{4}\right)(\mathrm{OX})\right] \mathrm{Zr}\left(\mathrm{NMe}_{2}\right)_{2}$ system. ${ }^{3 f}$ These values may also be

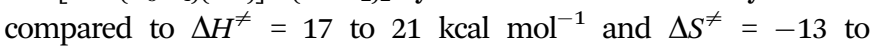
$-23 \mathrm{cal} \mathrm{K}^{-1} \mathrm{~mol}^{-1}$ in the salicyloxazoline zirconium system ${ }^{17}$ and $\Delta H^{\neq}=20.1 \pm 0.5 \mathrm{kcal} \mathrm{mol}^{-1}$ and $\Delta S^{\neq}=-21 \pm 1 \mathrm{cal} \mathrm{K}^{-1} \mathrm{~mol}^{-1}$ in

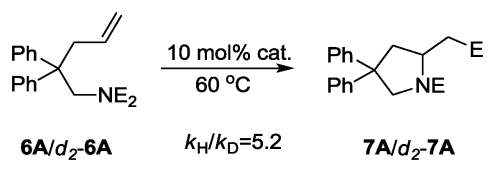

Scheme 3 Primary kinetic isotopic effect observed in the cyclization of $6 A(E=H / D)$. 


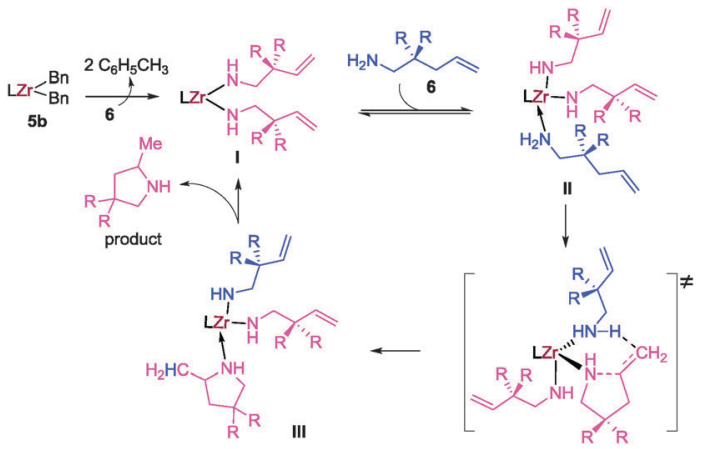

Scheme 4 Proposed catalytic cycle for intramolecular hydroamination

the tethered bis(ureate)zirconium system. ${ }^{18}$ The parameters obtained in the current study show a highly organized transition state.

Though $\mathbf{9}$ displayed a similar catalytic activity to that of $\mathbf{8}$ and $\mathbf{5 b}$, it was not clear whether a dinuclear species was involved in the turnover-limiting step of the catalytic cycle as the first-order dependence on precatalyst concentration was observed. Accordingly, experiments on the non-linear effect were carried out. A strict linear relationship between the ee values of $7 \mathbf{A}$ and those of precatalyst $\mathbf{5 b}$ was observed (see Fig. S22 in the ESI $\dagger$ ), as would be expected for the exclusively monomeric mechanism. In addition, the ${ }^{1} \mathrm{H}$ NMR spectrum showed that $\mathbf{9}$ dissociated into the monomeric form $[\mathrm{ONO}] \mathrm{Zr}\left(\mathrm{NHBu}^{\dagger}\right)_{2}$ in the presence of excess $t$ - $\mathrm{BuNH}_{2}$ (see Schemes $\mathrm{S} 1$ and S2 in ESI $\dagger$ ). These results suggest that the reaction may proceed via a mononuclear intermediate.

In addition, the isotopic substitution significantly affects the reaction's enantioselectivity, where the \% ee's for deuteropyrrolidines are systematically and significantly higher than the values for the corresponding proteo-pyrrolidines (see Table S7 in ESI $\dagger$ ). Such effects show that an N-H (or N-D) bond is involved in the stereochemistry-determining step, supporting a concerted $\mathrm{C}-\mathrm{H} / \mathrm{C}-\mathrm{N}$ bond forming mechanism. ${ }^{3 d}$

On the basis of aforementioned experimental data, a plausible catalytic mechanism is proposed in Scheme 4. Initial aminolysis of the precatalyst $\mathbf{5 b}$ by excess substrates liberates toluene to give a monomeric species I. The third substrate binds reversibly to the $\mathrm{Zr}$ atom to give the species II. Intramolecular hydroamination takes place via irreversible $\mathrm{C}-\mathrm{H}$ and $\mathrm{C}-\mathrm{N}$ bond formation through a highly ordered transition state. This is supported by a very large and negative value of $\Delta S^{\neq}\left(-53.4(9) \mathrm{cal} \mathrm{K}^{-1} \mathrm{~mol}^{-1}\right)$ as well as a large KIE value of 5.2. The dissociation of neutral pyrrolidine regenerates the active catalyst $\mathbf{1}$ to complete the catalytic cycle. Such a mechanism is similar to those reported in the literature. ${ }^{3 d, 18}$

In summary, this work describes our journey of exploring new chiral zirconium catalysts for asymmetric hydroamination/cyclization. Through systematic studies, we have developed a class of new pincerlike $\left[\mathrm{O}^{-} \mathrm{NO}^{-}\right] \mathrm{Zr}$ systems that can efficiently catalyze the hydroamination of primary aminoalkenes with up to $94 \%$ ee and $\geq 95 \%$ conversion. The catalyst structure-enantioselectivity relationships have also been addressed, which may shed some light on the ligand design of new catalyst systems. A mechanism has also been proposed to account for all of the experimental observations, which involves a highly ordered transition state and a concerted bond formation pathway.
We are grateful for the financial support from the National Natural Science Foundation of China (21121062 to YT) and the CAS-Croucher Funding Scheme.

\section{Notes and references}

1 (a) T. C. Nugent, Chiral Amine Synthesis: Methods, Developments and Applications, Wiley-VCH, Weinheim, Germany, 2010; (b) A. Ricci, Modern Amination Methods, Wiley-VCH, Weinheim, Germany, 2000.

2 (a) M. R. Gagné, L. Brard, V. P. Conticello, M. A. Giardello, C. L. Stern and T. J. Marks, Organometallics, 1992, 11, 2003; (b) M. A. Giardello, V. P. Conticello, L. Brard, M. Sabat, A. L. Rheingold, C. L. Stern and T. J. Marks, J. Am. Chem. Soc., 1994, 116, 10212; (c) K. Manna, M. L. Kruse and A. D. Sadow, ACS Catal., 2011, 1, 1637; (d) M. R. Gagne, C. L. Stern and T. J. Marks, J. Am. Chem. Soc., 1992, 114, 275.

3 (a) P. D. Knight, I. Munslow, P. N. O'Shaughnessy and P. Scott, Chem. Commun., 2004, 894; (b) M. C. Wood, D. C. Leitch, C. S. Yeung, J. A. Kozak and L. L. Schafer, Angew. Chem., Int. Ed., 2007, 46, 354; (c) A. L. Gott, A. J. Clarke, G. J. Clarkson and P. Scott, Chem. Commun., 2008, 1422; (d) K. Manna, S. Xu and A. D. Sadow, Angew. Chem., Int. Ed., 2011, 50, 1865; (e) G. Zi, X. Liu, L. Xiang and H. Song, Organometallics, 2009, 28, 1127; $(f)$ K. Manna, W. C. Everett, G. Schoendorff, A. Ellern, T. L. Windus and A. D. Sadow, J. Am. Chem. Soc., 2013, 135, 7235; (g) M. C. Hansen, C. A. Heusser, T. C. Narayan, K. E. Fong, N. Hara, A. W. Kohn, A. R. Venning, A. L. Rheingold and A. R. Johnson, Organometallics, 2011, 30, 4616; (h) J. M. Hoover, J. R. Petersen, J. H. Pikul and A. R. Johnson, Organometallics, 2004, 23, 4614.

4 (a) P. Horrillo-Martínez and K. C. Hultzsch, Tetrahedron Lett., 2009, 50, 2054; (b) J. S. Wixey and B. D. Ward, Chem. Commun., 2011, 47, 5449; (c) X. Zhang, T. J. Emge and K. C. Hultzsch, Angew. Chem., Int. Ed., 2012, 51, 394.

5 (a) P. H. Martinez, K. C. Hultzsch and F. Hampel, Chem. Commun., 2006, 2221; (b) T. Ogata, A. Ujihara, S. Tsuchida, T. Shimizu, A. Kaneshige and K. Tomioka, Tetrahedron Lett., 2007, 48, 6648; (c) J. Deschamp, J. Collin, J. Hannedouche and E. Schulz, Eur. J. Org. Chem., 2011, 3329.

6 (a) X. Shen and S. L. Buchwald, Angew. Chem., Int. Ed., 2010, 49, 564; (b) B. W. Turnpenny, K. L. Hyman and S. R. Chemler, Organometallics, 2012, 31, 7819; (c) Z. Zhang and R. A. Widenhoefer, Angew. Chem., Int. Ed., 2007, 46, 283; (d) Z. Zhang, S. D. Lee and R. A. Widenhoefer, J. Am. Chem. Soc., 2009, 131, 5373; (e) G. L. Hamilton, E. J. Kang, M. Mba and F. D. Toste, Science, 2007, 317, 496.

7 (a) S. Hong, S. Tian, M. V. Metz and T. J. Marks, J. Am. Chem. Soc., 2003, 125, 14768; (b) X. Yu and T. J. Marks, Organometallics, 2007, 26, 365.

8 P. N. O'Shaughnessy, P. D. Knight, C. Morton, K. M. Gillespie and P. Scott, Chem. Commun., 2003, 1770.

9 (a) J. Collin, J.-C. Daran, E. Schulz and A. Trifonov, Chem. Commun., 2003, 3048; (b) J. Hannedouche, I. Aillaud, J. Collin, E. Schulz and A. Trifonov, Chem. Commun., 2008, 3552; (c) I. Aillaud, K. Wright, J. Collin, E. Schulz and J. P. Mazaleyrat, Tetrahedron: Asymmetry, 2008, 19, 82; (d) Y. Chapurina, J. Hannedouche, J. Collin, R. Guillot, E. Schulz and A. Trifonov, Chem. Commun., 2010, 46, 6918; (e) Y. Chapurina, H. Ibrahim, R. Guillot, E. Kolodziej, J. Collin, A. Trifonov, E. Schulz and J. Hannedouche, J. Org. Chem., 2011, 76, 10163.

10 (a) D. V. Gribkov, K. C. Hultzsch and F. Hampel, Chem. - Eur. J., 2003, 9, 4796; (b) D. V. Gribkov, K. C. Hultzsch and F. Hampel, J. Am. Chem. Soc., 2006, 128, 3748; (c) A. L. Reznichenko, H. N. Nguyen and K. C. Hultzsch, Angew. Chem., Int. Ed., 2010, 49, 8984.

11 (a) J. Y. Kim and T. Livinghouse, Org. Lett., 2005, 7, 1737; (b) N. Meyer, A. Zulys and P. W. Roesky, Organometallics, 2006, 25, 4179; (c) P. Benndorf, J. Jenter, L. Zielke and P. W. Roesky, Chem. Commun., 2011, 47, 2574.

12 (a) L. Xiang, Q. Wang, H. Song and G. Zi, Organometallics, 2007, 26, 5323; (b) G. Zi, L. Xiang and H. Song, Organometallics, 2008, 27, 1242.

13 N. D. Shapiro, V. Rauniyar, G. L. Hamilton, J. Wu and F. D. Toste, Nature, 2011, 470, 245.

14 (a) K. Mikami and M. Lautens, New Frontiers in Asymmetric Catalysis, J. Wiley and Sons, Inc., Hoboken, NJ, 2007; (b) B. List, Asymmetric Organocatalysis, Springer, New York, 2010.

15 X. Wang, Z. Chen, X.-L. Sun, Y. Tang and Z. Xie, Org. Lett., 2011, 13, 4758. 16 C. He, J. Ke, H. Xu and A. Lei, Angew. Chem., Int. Ed., 2013, 125, 1527.

17 L. E. N. Allan, G. J. Clarkson, D. J. Fox, A. L. Gott and P. Scott, J. Am. Chem. Soc., 2010, 132, 15308.

18 D. C. Leitch, R. H. Platel and L. L. Schafer, J. Am. Chem. Soc., 2011, 133, 15453 . 